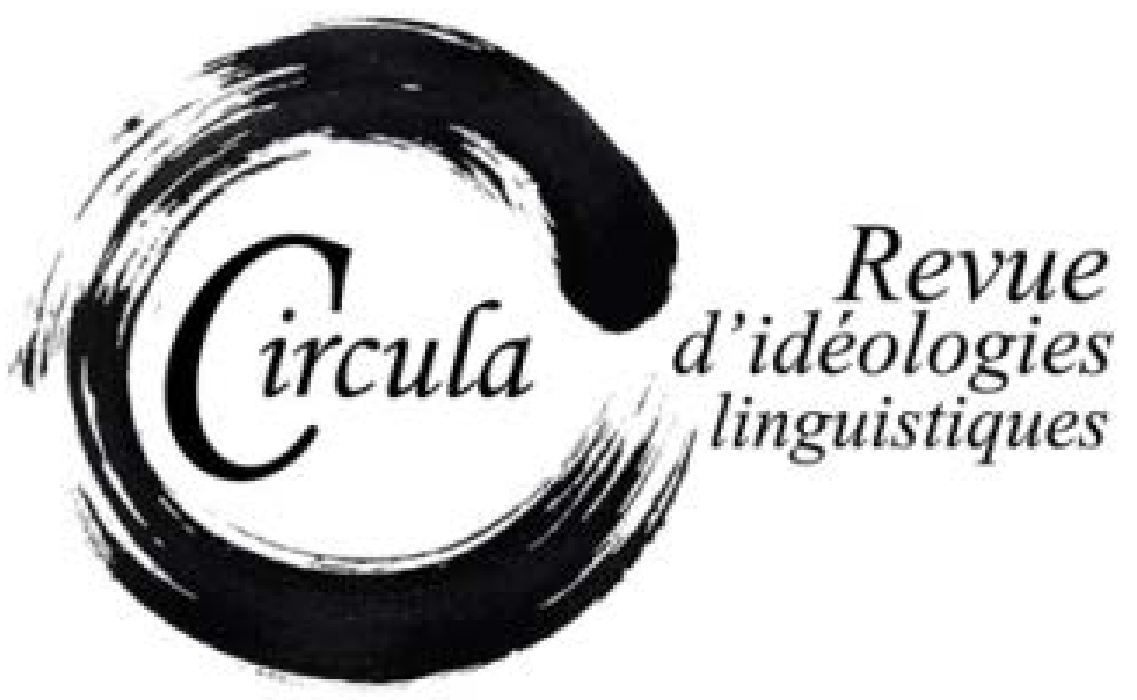

TITRE: ¿QUÉ ES EL PURISMO?

Auteur(s): MArie-ÉGlantine Lescasse, Université de PARIS-SORbOnNe

Revue: CiRCula, numÉRO 8 - IDEOLOGíAs EN ObRAS SOBRE LA LENGUA ESPAÑOLA (SS. XV-XX)

PAgES: $100-128$

ISSN: 2369-6761

Directeurs: : Francisco Escudero Paniagua, Carlos Villanueva García, Carmen Quijada Van DEN BERGHE, José Jesús Gómez AsEnCIO

URI: HTTP://HDL.HANDLE.NET/11143/14495

DOI: HTTPS://DOI.ORG/10.17118/11143/14495 


\section{¿Qué es el purismo?}

Marie-Églantine Lescasse, Université de Paris-Sorbonne marie-eglantine. lescasse.2@ paris-sorbonne.fr

Resumen: El presente artículo busca echar luz sobre la mentalidad de los autores castellanos puristas de los siglos XVI y XVII, mediante el análisis de las representaciones (imágenes, metáforas, ideas) asociadas con la lengua bella y pura, en el corpus de elogios de la lengua publicado por Germán Bleiberg en 1951. Nos apoyamos en las teorías antropológicas de Mary Douglas para mostrar que los puristas llevan a cabo una forma de sacralización del idioma. Además, mostramos que se caracterizan menos por un conjunto de doctrinas explícitas que por un apego sentimental a la lengua materna, un amor superlativo e irracional. Esto se percibe a través del uso de una retórica hiperbólica, así como de las personificaciones femeninas, que erotizan a la lengua.

Palabras claves: imaginaire linguistique; purismo; sentimiento de la lengua; antropología; pureza

Summary: This paper aims at shedding a new light upon Castilian purists' psychology in the $16^{\text {th }}$ and $17^{\text {th }}$ centuries, thanks to the analysis of their imagery and mental representations (metaphors and ideas about pure, beautiful language). Our corpus consists of the 22 modern texts of Germán Bleiberg's Anthology of praises of Castilian language, published in 1951. I make use of Mary Douglas' anthropological theories to show that purists tend to sacralize Castilian language. Moreover, I show that purists don't have a set of explicit doctrines, but are driven by a strong sentimental feeling to their maternal language, which expresses itself in terms of an irrational and powerful love, as well as of a full self-identification with their language. The use of hyperbolic rhetoric and the abundance of feminine personifications are some of the features of the erotization of Castilian.

Key words: imaginaire linguistique; purism; attitudes towards language; anthropology; purity 


\section{Introducción}

Este artículo ${ }^{1}$ tiene como objetivo echar luz sobre la mentalidad purista en los siglos XVI y XVII mediante el análisis de las representaciones (imágenes, metáforas, ideas) asociadas con la lengua bella y pura.

El purismo ha sido definido por George Thomas (Thomas, 1991)², y se le han dedicado monografías (Vitale, 1986; Paveau, 2008) y antologías (Jervis Jones, 1995) nacionales; sin embargo, en el caso del castellano, el purismo nunca ha sido estudiado como tal, y menos lo ha sido en su forma precoz, la de la época clásica. Disponemos, es cierto, de un fundamental estudio de Lucia Binotti sobre la teoría del castellano primitivo (Binotti, 1995), pero este se focaliza más bien en los argumentos doctrinales, y no hace hincapié sobre el fuerte componente imaginario y afectivo de las ideas de unos y otros. La ideología de los puristas, y las imágenes en las que se apoya, fue rápidamente delineada por George Thomas, pero el autor no llegó a apoyar su demostración con textos concretos, por lo que solo la percibimos en términos muy generales (Thomas, 1991: 19)³. La psicología purista fue objeto de unos apuntes en el artículo de Mirambel sobre los movimientos puristas griegos del siglo XX (Mirambel, 1958) ${ }^{4}$ y de un interesante párrafo de la monografía ya mencionada de Thomas (Thomas, 1991) ${ }^{5}$.

Nuestro estudio se sitúa pues en la continuación de estos trabajos. En cuanto a la metodología, seguimos los pasos de Anne-Marie Houdebine, quien acuñó el concepto de "imaginaire linguistique" - el conjunto de representaciones, metáforas, imágenes, analogías, asociadas con la lengua - (Hou-

1. Le agradezco sinceramente a Mercedes Blanco sus lecturas, correcciones y comentarios, que constituyeron una ayuda muy valiosa para la redacción de este trabajo.

2. Lo define asi: "Purism is the manifestation of a desire on the part of a speech community (or some section of it) to preserve a language from, or rid of it, putative foreign elements or other elements held to be undesirable (including those originating in dialects, sociolects and styles of the same language)." (Thomas, 1991: 12).

3. Distingue siete grupos de imágenes asociadas con la figura del purista: el molinero, el jardinero, el metalúrgico, el molendero, el médico, el genealogista, el párroco (Thomas, 1991: 19-23).

4. Mirambel describe el purismo como una religión, reservada a iniciados, y a los puristas como partidarios de la autoridad, de lo sagrado frente a lo profano, pero sin llevar más lejos el análisis: "Le purisme grec s'est comporté à la manière d'un fait religieux. [...] Cette position est en tout point comparable à celle d'une religion se référant à un texte sacré, contenant une vérité 'révélée.' [...] Le purisme répugne à l'effort humain, individuel et collectif, actuel, pour préférer l'autorité. C'est ici une forme de l'opposition du sacré au profane. [...] Le purisme [...] ne cherche de justification que dans l'autorité de l'archaïsme, et non dans l'exigence du présent" (Mirambel, 1964: 434).

5. "[...] in as much as purism is an attitude towards language it also needs to be examined from the reference point of the social psychology of language." (Thomas, 1991: 2) y "Mary Douglas's work sheds some light on the personality of the purist: he abides strictly by a set of rules and regulations, abhors grey areas, and condemns the actions of those who transgress the rules. [...] The purist may be characterized, then, as a strictly orthodox in his beliefs, unyielding to change, intolerant of the transgression of others, and fiercely repressive of any desires within himself to cross the same bounds." (Thomas, 1991: 34). 
debine, 2002: 11-21), y de Cécile Canut (1998), quien reflexionó sobre el componente psicológico de los "discursos epilingüísticos".

Partimos de la siguiente observación: las prescripciones puristas en torno al "bien hablar" nunca son explícitas, ni precisas, por lo que algunos autores las describieron como normas "borrosas", sin definir (Siouffi et Steuckardt, 2007: 11; Jenny, 2005: §3). Nuestra hipótesis de trabajo es entonces la siguiente: los puristas proyectarían sobre la lengua pura un conjunto de imágenes, sentimientos, ideas, que se corresponden con una mentalidad particular que en nuestro parecer los caracteriza y define, y que intentamos delinear en lo que sigue.

Antes de proceder al análisis de textos puristas, objeto de este artículo, definiremos de manera provisional a los puristas como los autores que corresponden con las definiciones dadas por Georges Thomas ${ }^{8}$ y Jean-Claude Milner (el "amor a la lengua"), que explicaremos a continuación. Por esa razón, los elogios de la lengua castellana, como manifestaciones de una admiración por la lengua propia, serán considerados como puristas. Por supuesto, no todos los elogios de la lengua fueron escritos por autores puristas9: se trata de una definición provisional que guió nuestra elección del corpus.

Este consiste en los 22 textos modernos editados por Germán Bleiberg en 1951 en su Antología de elogios de la lengua española: son textos que fueron escritos entre 1492 y 1672, y que contienen todos un elogio de la lengua castellana. Los autores son lingüistas (Nebrija, Correas), humanistas (Valdés, Mejía, Villalón, Morales, Venegas, Arias Montano, Viziana, Herrera, Medina, Aldrete, Cabrera de Córdoba, Pellicer), religiosos (fray Cristóbal de Fonseca, Pedro Malón de Chaide, Pedro de Vega, Jerónimo de San José, Juan de Robles), escritores (Cervantes, fray Luis de León), quienes reflexionaron sobre los orígenes de la lengua castellana y sus cualidades retóricas (elegancia, dulzura, honestidad...): el elogio de la lengua y la enumeración de sus cualidades bajo forma de epítetos laudatorios se volvió un topos de la literatura humanística, ya desde los años 1530 (Binotti, 1995). El mayor interés de esta antología ${ }^{10}$, además de proporcionar gran cantidad de pasajes puristas, es que contiene textos raros o muy difíciles de encontrar, como los Equívocos morales del doctor Viana, de autor y fecha descono-

6. La noción de discurso epilingüístico reenvía a "'ensemble des jugements, évaluations et catégorisations des locuteurs sur les pratiques langagières et sur les lectes", "évaluations subjectives sur les lectes n'impliquant aucun savoir linguistique spécifique" (Canut 1998: en línea, §3).

7. Expresión recurrente bajo la pluma de los autores de nuestro corpus (definido a continuación), empleada en competencia con "bien decir". Aparece la expresión dos veces en Fonseca, una vez en Jerónimo de San José, una vez en Medina, y hasta siete veces en Morales, mientras que el sintagma "bien hablar" aparece una vez en fray Luis, una en Jerónimo de San José, y cinco veces en Morales.

8. Véase la nota 2.

9. Pero creemos que todos (o casi todos) los autores puristas escribieron un elogio de su lengua materna.

10. La antología de Bleiberg cubre desde el siglo XV hasta el siglo XX. En cuanto a la parte moderna, se trata de los mismos textos que escogió José Francisco Pastor en su recolección titulada Las apologías de la lengua castellana en el siglo de oro (1929), excepto que añade Bleiberg a este florilegio la Población y lengua primitiva de España (1672) de José de Pellicer. 
cidos, y, sobre todo, el famoso Discurso sobre la lengua castellana de Ambrosio de Morales ${ }^{11}$, escrito en 1550 pero sólo publicado en 1772, en el volumen Obras que Francisco Cervantes de Salazar ha hecho, glosado y traducido, junto con obras de Fernán Pérez de Oliva y Juan Luis Vives. Sin embargo, no aparece el Diálogo de Morales entre estos textos en el ejemplar digitalizado por la BNE, y no ha recibido tampoco edición moderna, por lo que la transcripción de Bleiberg resulta muy valiosa.

A estos 22 textos hemos sumado otros 5, que nos parecían emblemáticos de las definiciones de Thomas y Milner: la Elocuencia española en arte (1604) del rétor Bartolomé Jiménez Patón (1993), los Discursos de la antigüedad de la lengua cántabra vascongada (1607) del escritory pintor vasco Baltasar Echave de Orio, el Discurso poético (1624) de Juan de Jáuregui (2016), las Epístolas de la Filomena (1621) de Félix Lope de Vega Carpio (2015) y el Cuento de cuentos (1626) de Francisco de Quevedo. Habría por supuesto que ampliar el corpus, por lo que no se trata aquí de un estudio exhaustivo, sino de una primera aproximación al fenómeno del purismo español de los siglos XVI y XVII.

También, puesto que el purismo es definido como una actitud frente a la lengua (Thomas 1991: 2), ésta puede manifestarse de manera puntual y localizada en textos que en su conjunto no son puristas. Hablamos por comodidad de "textos puristas", pero de hecho deberíamos hablar de "pasajes que delatan una mentalidad o una actitud purista ante la lengua".

Tras recordar el significado antropológico del concepto de pureza, estudiaremos en un primer momento los fenómenos de sacralización de la lengua en estas declaraciones de carácter purista, a través de las imágenes de la frontera y de la suciedad corporal. En un segundo momento, analizaremos los modos del fetichismo purista en torno a la lengua y su erotización, mediante el recurso a la personificación femenina. Finalmente, estudiaremos la influencia del pensamiento religioso en las ideas lingüísticas y la afinidad entre pureza lingüística, pureza espiritual y pureza corporal.

\section{Antropología del purismo. La sacralización de la lengua}

\subsection{El concepto de pureza en antropología}

Desde el siglo XIX, el concepto de pureza fue estudiado en antropología e historia de las religiones como parte de la dicotomía puro/impuro, que tiene estrechas conexiones con lo sagrado y el tabú (Frevel y Nihan, 2013: 3-4; Douglas, 1966: 10 y ss.). No estudiaremos aquí estas interconexiones, sino que sólo delinearemos las características esenciales de la definición de lo puro en antropología, para después aplicarlas al purismo lingüístico.

11. Importante por múltiples razones, entre las cuales por constituir la fuente del prólogo interesantísimo de Bartolomé Jiménez Patón a su Elocuencia española en arte (1604). 
Lo puro designa lo que no es tocado o contagiado por una persona, objeto o animal impuro. Esta definición resulta tautológica ya que implica la, previa, de lo impuro, que lleva la precedencia conceptual. Seguimos aquí el análisis luminoso de Jankélévitch, quien describe la pureza como algo inefable, marcado por esta tautología constitutiva:

Avec l'impur, à la bonne heure ! voilà de beaux jours en perspective pour la description ou la narration... Sur l'être impur beaucoup à dire, et même tout à dire ! - Rien à dire au contraire sur la très vide pureté. [...] la pureté absolue ou irrelative ne se prête qu'à une fascinante tautologie. (Jankélévitch, 1960: 10 y 12)

La pureza no se deja definir, si no es mediante la definición inversa de lo impuro: "On a beau faire, pour parler de la pureté il faut parler d'autre chose, et notamment de l'impur" (Jankélévitch, 1960: 14). La pureza en sí es indescriptible porque es simple, es una "positividad sin contenido", o sea que no se deja analizar, e inenarrable porque es inmóvil, perfecta, inmutable (Jankélévitch, 1960: 13)12. Para entender qué es lo puro, tenemos entonces que definir primero lo impuro.

Son muchos los autores que lo han definido por extensión, mediante enumeraciones de objetos o personas tradicionalmente considerados como impuros (enfermos, mujeres que acaban de dar a luz o con sus menstruaciones, etc. $)^{13}$. El Levítico, en el que se da la lista de los animales que no deben ser tocados ni comidos por los judíos ${ }^{14}$, constituye un ejemplo clásico. Sin embargo, una definición por intensión parece casi tan imposible de proveer como la de lo puro, por lo que Mary Douglas escribe:

12. Según Mary Douglas, esto se debe a que, dentro de un sistema social, lo puro constituye el estado "normal", esperado, no alterado de las cosas (su definición es negativa), mientras que lo impuro designa lo que ha sido modificado, lo que resulta de una acción o acontecimiento indeseables (definición positiva): "Quand il s'agit des usages sociaux, nous avons remarqué qu'impureté' implique un jugement beaucoup plus fort que 'pureté.' Dans les sociétés européennes, et bien souvent ailleurs, 'impur' est le langage du reproche. [...] [...] ['Pur',] cela évoque de bonnes qualités et ne demande aucune action. Alors qu'impur' justifie un rejet. C'est une accusation, une exécration. [...] La pureté a tendance à représenter la norme, l'idéal attendu, tenu pour acquis jusqu'à ce qu'il soit trahi. L'impureté est une intrusion sociale, une brèche dans la frontière, une chose exécrable. Dans la vie sociale, l'homme adultère est comme un voleur, un violeur. Un vêtement que l'on estime sale, un honneur que l'on juge atteint sont souillés, tachés, marqués, un élément leur a été ajouté. [...] Tout cela implique que la pureté est naturelle tandis que l'impureté est une difformité." (Douglas, 1998: § 18-19).

13. Pensamos en las listas de Edmund Leach y Mary Douglas (Leach, 1989: 38; Douglas, 1966: 122 y 125).

14. "Habló Jehová a Moisés y a Aarón, diciéndoles: Hablad a los hijos de Israel y decidles: Estos son los animales que comeréis de entre todos los animales que hay sobre la tierra. De entre los animales, todo el que tiene pezuña hendida y que rumia, este comeréis. Pero de los que rumian o que tienen pezuña, no comeréis estos: [...] Y por estas cosas seréis inmundos; cualquiera que tocare sus cuerpos muertos será inmundo hasta la noche, y cualquiera que llevare algo de sus cadáveres lavará sus vestidos, y será inmundo hasta la noche" (Biblia, Levítico, 11, 1-24). 
Toutefois, il n'a jamais été répondu à la question suivante: pourquoi Dieu considère-t-il certains animaux comme impurs et d'autres comme abominables? Selon les croyances religieuses habituelles, il est bel et bon que, de même que le Créateur a créé les animaux et les humains, de même, il a interdit à ces derniers de manger la plupart des animaux. Mais pourquoi a-t-il dit que les animaux interdits de consommation sont impurs, et pour quelles raisons a-t-il donc créé des êtres détestables? (Douglas, 1998: §4)

Deducir una regla general que caracteriza a todas las cosas y seres que se juzgan impuros, resulta entonces muy delicado. Si nos fijamos en los ejemplos mencionados arriba, parece que todos son entidades ambiguas, seres que se apartan de la norma. Todos tienen algo mezclado: el cerdo tiene pezuña hendida pero no rumia como el ciervo, la sangre menstrual de las mujeres es un fluido que circula entre medio interior y entorno, volviendo borrosas las fronteras del cuerpo, el enfermo está invadido por microbios que lo asaltan desde lo exterior.

Hay otro elemento que caracteriza las cosas impuras, y que se deriva directamente del primero: su poder de contagio. Las cosas colocadas en las fronteras siempre amenazan pasar de lo exterior a lo interior. En su artículo de 1998, Mary Douglas propone así quitar las connotaciones morales de la palabra "impuro", para entenderla como sinónimo de lo contagiado ${ }^{15}$ (Douglas, 1998: §22). Lo impuro es pues la persona, objeto o animal que contagia su entorno por contacto, que está colocada en un lugar donde no debería, y entonces debe ser separado de la comunidad: según los clásicos análisis de Purity and danger, lo sucio es materia desplazada ("matter out of place").

Apartar lo impuro equivale entonces a restablecer un orden perdido: "Dirt offends against order. Eliminating it is not a negative movement, but a positive effort to organize the environment" (Douglas, 1966: 2) ${ }^{16}$. Se trata de evitar las mezclas, las interacciones con elementos exógenos, que se estiman peligrosas para la integridad del cuerpo, tanto a nivel individual (hay que protegerse de la enfermedad) como social (hay que preservar la sociedad del desorden).

\subsection{Frontera e imágenes de separación o la sacralización de la lengua}

Ahora bien, esta cualidad de "ser apartado de la comunidad" es lo que define lo sagrado en historia de la religión. En las Formas elementales de la vida religiosa, Émile Durkheim, tras haber definido la creencia religiosa como división del mundo entre lo profano y lo sagrado (Durkheim, 2015: 79 y ss), definía precisamente lo sagrado como lo que una prohibición divina aparta y protege de toda

15. Su proposición concernía únicamente la traducción e interpretación del Levítico, pero creemos que se puede aplicar a lo impuro de manera más general. Roger Caillois también insistió en esta noción de contagio para definir lo impuro, en L'homme et le sacré : "'impur en est banni [de la communauté] afin qu'il ne communique pas sa souillure à ce qui l'entoure" (Caillois, 1950: 52).

16. "In chasing dirt, in papering, decorating, tidying we are not governed by anxiety to escape disease, but are positively re-ordering our environment, making it conform to an idea. There is nothing fearful or unreasoning in our dirt-avoidance: it is a creative movement, an attempt to relate form to function, to make unity of experience." (Douglas, 1966: 2). 
contaminación, y cuyo contacto o cercanía están vedados: "Les choses sacrées sont celles que les interdits protègent et isolent; les choses profanes, celles auxquelles ces interdits s'appliquent et qui doivent rester à distance des premières." (Durkheim, 2015: 83). Tanto lo impuro/puro como lo sagrado suponen la idea de una separación entre dos mundos impermeables que deben permanecer totalmente herméticos el uno al otro ${ }^{17}$. La transgresión de esta frontera simbólica, el contacto nefasto entre seres de esencia distinta (sagrada/profana, pura/impura) ${ }^{18}$ implica un peligro para el orden del mundo.

Ahora bien, los puristas aplican a la lengua un concepto de la pureza que, además de su significación lingüística -vamos a verlo-, también se colorea de este significado antropológico de lo puro. George Thomas ya había notado que las teorías de Mary Douglas encajaban perfectamente con la actitud purista de prescripción lingüística (Thomas, 1991: 33). La pureza de la lengua, o sea su carácter desprovisto de faltas, solecismos, barbarismos, que la deturpan ${ }^{19}$ (definición lingüística), se corresponde también para ellos con su homogeneidad e integridad, descritas en términos de limpieza (definición antropológica) ${ }^{20}$. Así, dentro de lo que George Thomas llamó "purismo xenofóbico"21 -que no es la única forma de purismo-, se trata de "limpiar" el idioma de toda "invasión" por vocablos extranjeros $^{22}$. Thomas llamaba la atención sobre la noción de frontera, esencial para entender la psicología purista, aplicando la conceptualización de Mary Douglas a la pureza lingüística, tal como la perciben los puristas:

17. "Il n'existe pas dans l'histoire de la pensée humaine un autre exemple de deux catégories de choses aussi profondément différenciées, aussi radicalement opposées l'une à l'autre. [...] le sacré et le profane ont toujours été conçus par l'esprit humain comme des genres séparés, comme deux mondes entre lesquels il n'y a rien de commun" (Durkheim, 2015: 81).

18. "Parce que la notion de sacré est, dans la pensée des hommes, toujours et partout séparée de la notion du profane, par ce que nous concevons entre elles une sorte de vide logique, l'esprit répugne invinciblement à ce que les choses correspondantes soient confondues ou simplement mises en contact; car une telle promiscuité ou même une contigüité trop directe contredisent trop violemment l'état de dissociation où se trouvent ces idées dans les consciences. La chose sacrée, c'est, par excellence, celle que le profane ne doit pas, ne peut pas impunément toucher." (Durkheim, 2015: 8283). Aquí Durkheim no habla del contagio de lo impuro, pero nos parece que la heterogeneidad esencial, la separación obligatoria y el contacto nefasto (promiscuité, contigüité) entre sagrado y profano son muy similares a las que apartan lo impuro de lo puro.

19. El rétor Bartolomé Jiménez Patón escribe que la lengua pura va "corregida y enmendada de solecismos y barbarismos" (Jiménez Patón, 1993: 115).

20. George Thomas recuerda que uno de los conceptos importantes del purismo lingüístico es el de integridad: "Purity', the condition of being 'pure' [...] refers to a set of core meanings, including 'homogeneity', 'wholeness', and 'oneness'." (Thomas, 1991: 31).

21. "Xenophobic purism involves the eradication or replacement of foreign elements, whether their source is specified (targeted xenophobia) or unspecified (general xenophobia)." (Thomas, 1991: 80-81).

22. Utilizamos aquí adrede este vocabulario de la guerra, conforme con las metáforas desarrolladas por los mismos puristas: ellos crean un imaginario político y territorial de la frontera y de la ciudadanía. 
The need to preserve national linguistic identity by differentiating and distancing the language from its competitors finds a ready explanation in the pollution theories of Mary Douglas. The system is defined by pronouncing certain elements as not belonging or impure. Any transgression of these defining boundaries comes to be viewed as a threat to the system as a whole. Puristic ritual expresses anxiety about the need to protect the 'orifices', the sociological counterpart of which is the 'care to protect the political and cultural unity of a minority group' (Douglas 1966: 124). (Thomas, 1991, 44, subrayado nuestro)

En nuestro corpus, el imaginario de la frontera se halla sobre todo en Jáuregui, quien utiliza en su Discurso poético (1624), dirigido contra Góngora, la metáfora del exilio para describir a los poetas que introducen palabras extranjeras en su discurso: "Así que el huir de palabras comunes los destierra a lenguas extrañas donde cometen mayores vicios"23. "Lenguas" sustituye aquí a "tierras", y el complemento de lugar "a lenguas extrañas", introducido por la preposición espacial directiva "a”, seguida de la subordinada de lugar (“donde..."), dibuja una territorialización de los idiomas, representados como tierras delimitadas por una frontera que no hay que traspasar. El que franquea esta frontera pierde lo que podríamos Ilamar su ciudadanía lingüística, se vuelve extranjero, ostracizado, condenado a errar fuera del espacio común, el espacio político e identitario de la lengua compartida ${ }^{24}$. Esta representación de una separación nítida entre las lenguas, y el exilio del que se aventura fuera de la suya, expresa este afán de ausencia de mezcla.

La lengua materna tiene que ser apartada, bien delimitada y protegida de influencias externas: se vuelve sacra, no se debe modificar, tocar, contagiar, se asocia con un precepto transcendente que los puristas no llegan a justificar, pero que tiene vigencia en su imaginario. Asistimos pues a una sacralización de la lengua.

\subsection{Imágenes de la suciedad y la purificación ritual}

Los puristas desarrollan también, conforme con la separación religiosa de lo puro (limpio, sano) y lo impuro (sucio, enfermo), un imaginario de la suciedad, al utilizar palabras como "ensuciar" para calificar la introducción de vocablos extraños dentro de la lengua castellana. Martín de Viziana, noble valenciano, autor de una Alabanza de las lenguas hebrea, griega, latina, española y valenciana (1574), hablando de los soldados y mercaderes que vuelven de tierras lejanas, escribe así:

23. No hemos encontrado la metáfora del exilio en otro autor, por lo que constituye un hápax, pero esta imagen resulta esencial para entender la mentalidad purista.

24. Ver más abajo sobre la importancia del idioma como cemento de la comunidad nacional. 
Otros hay, que pues su ventura los libró de las heridas, y de la muerte, y volvieron vivos a su tierra, por mostrar que allá sirvieron, traen dos docenas de vocablos extraños, y háblanlos, y péganlos a su lengua castellana. Y ya que esto se hace, si fuese de otra lengua buena como la castellana, aun sería de sufrir; pero a las veces es de alguna ruin lengua y en lugar de honrar su lengua, ensúcianla, y de esta manera es lengua compuesta de muchas. (Viziana, 1951: 33)

Viziana no dice explícitamente de qué "ruin lengua” está hablando, pero como acaba de vituperar la lengua árabe, usando adjetivos muy similares ("civil y abatida") para calificarla², podemos pensar que se trata de esta. Aquí por supuesto, el purismo lingüístico se mezcla con odio racial, en un período de enfrentamiento entre cristianos y moriscos en Granada y Valencia (Woolard, 2002).

No es el purismo xenófobo el único en sacralizar el idioma. Desde una perspectiva elitista ${ }^{26}$, se trata también de proteger la lengua contra los usos lingüísticos populares. Francisco de Quevedo desarrolla en el Cuento de cuentos (1626) este tema de lo sucio, aplicándolo a maneras de hablar vulgares: refranes, muletillas y estereotipos de lenguaje. Se mofa de estos al redactar un texto basado en su empleo exclusivo, inspirándose en las Cartas en refranes de Esteban de Garibay. Aquí, otra vez, la reflexión de Thomas sobre la mentalidad purista nos será útil para la interpretación. El autor describe el acto religioso de purificación necesitado por el contacto con lo impuro como una acción catártica:

If [...] impurities are seen to be a hindrance to religious practice by threatening to defile the sanctity of some person, object, place or act, they must be annulled through a ritual act of cleansing, often involving some form of purging, sacrifice or penance. These ritual acts of purification have a cathartic value: that which was unclean is made clean; and the threat to the sanctity of the object, person, place or act is removed. Purification, then, is a ritualistic response to undo the effects of unclean elements, which threaten the margins of the religious system. (Thomas, 1991: 30)

Creemos que se puede aplicar este análisis al purismo lingüístico, y en particular a este texto de Quevedo. Así, ya en el subtítulo, el autor se refiere a las "vulgaridades rústicas" como "barridas de la conversación" 27 , desechos que hay que descartar, y a continuación como escorias que hay que eliminar de una vez del habla: "Yo, por no andar rascando mi lenguaje todo el día, he querido espulgarle de una vez en esta jornada, donde yo solo no tengo qué hacer. Y en este cuento he sacado a la vergüenza todo el asco de nuestra conversación" (Quevedo, 1987: 153, subrayado nuestro). Al hablar de "barridas" y luego de la necesidad de expulgarlas, Quevedo presenta los estereotipos lingüísticos como parásitos, organismos exógenos indeseables e invasivos, sucios y asquerosos. La expresión

25. Según Viziana, la lengua castellana recibió perjuicio "en consentir que de la más que civil y abatida lengua arábiga tome vocablo ni nombre alguno [...]” (Viziana, 1951: 42).

26. George Thomas define así el purismo elitista: "[...] elitist purism embodies a negative, proscriptive attitude to substandard and regional usage." (Thomas, 1991: 78-79).

27. Quevedo, 1987: 149. 
hiperbólica de su asco ("he sacado a la vergüenza todo el asco de nuestra conversación"28) recalca el carácter impuro de las muletillas, que contagian el lenguaje.

Sobre todo, en este texto aparece otra vez la idea de que la lengua pura tiene que ser apartada y protegida de ataques exteriores: el prefijo "ex" (en "expulgar") expresa la delimitación corporal, casi topográfica, entre lo puro y lo impuro, lo interiory lo exterior, lo mío y lo ajeno, el cuerpo y el entorno. Cuando elementos procedentes del exterior comienzan a invadir el interior, se vuelven impuros, y amenazan la integridad del cuerpo, normalmente hermético: la heterogeneidad es factor de peligro.

El concepto de lo impuro es pues muy amplio y puede aplicarse tanto a palabras extranjeras -y el criterio de la pureza sería la homogeneidad lingüística-, o a expresiones populares -y entonces el criterio de lo puro sería la propiedad y el control del propio lenguaje.

\section{El amor a la lengua}

\subsection{El purismo como amor a la lengua propia}

El segundo eje importante del imaginario purista es el que gira en torno al amor de la lengua. En su libro L'amour de la langue, el lingüista y psicoanalista Jean-Claude Milner dibuja un paralelismo entre los gramáticos y puristas de hoy, por un lado, y los analogistas y anomalistas de la Antigüedad por el otro (Milner, 1978: 33). Los puristas, como los anomalistas antiguos, consideran que el saber sobre la lengua no se deja clasificar, ordenar mediante un sistema de reglas, ni "matematizar", sino que se transmite por iniciación (Milner, 1978, 34); la lengua sería "irrepresentable", y entonces funcionaría como tesoro de anomalías valiosas:

On méconnaît aisément ce qui est en jeu dans le purisme ; rien de moins que ceci : à être tenue pour un réel irreprésentable, la langue peut fonctionner comme agalma, trésor, objet. La 'pureté' devient cause d'un désir, et le puriste est le sujet à qui elle fait signe dans la langue. Alors, c'est bien d'un véritable amour qu'il s'agit, l'amour même de la langue [...]. (Milner, 1978: 35).

La imagen del tesoro significa que los puristas atribuyen al idioma un valor extremo, como a algo escaso y valioso, que hay que conservar con celo en un arca, apartado de las miradas extranjeras. Esta imagen, presente en los mismos puristas del XVI29, indica una adoración, que podríamos calificar de "fetichista", de la lengua ${ }^{30}$.

28. Quevedo, 1987: 153.

29. Como en Francisco de Medina: "somos, diré, tan descuidados o tan ignorantes que dejamos perderse a este raro tesoro que poseemos" (Medina, 1951: 95-96)

30. Pierre Bourdieu y Boltanski ya hablaron de "fetichismo de la lengua" para referirse a la obsesión de los franceses por el buen uso. (Bourdieu et Boltanski, 1975). 
Quisiéramos ahora hacer nuestro este análisis para entender el apego fuertísimo e irracional que se transparenta muchas veces en los textos de los puristas: lo que los caracterizaría, no sería el contenido de su doctrina, que es muy cambiante y borrosa, sino una psicología, una actitud, y un vínculo especial con la lengua materna, que sería el de un amor irreprensibley, vamos a verlo, casi neurótico.

\subsection{Retórica hiperbólica e identificación del locutor con su idioma: la neurosis purista}

Así, el escritor y gramático purista Cristóbal de Villalón escribe en su Gramática castellana (1558): "quiero tanto la mía, que no la daría por cuantas hay en el mundo" (Villalón, 1558: 37). La correlación intensiva (tanto... que...) asociada con el pronombre tónico "la mía" expresa esta adoración del sujeto purista por su lengua materna. Encontramos en el texto de Viziana casi la misma expresión ("no la dejen por otra del mundo"31), con la misma extraña hipótesis de la posibilidad del abandono, y la retórica hiperbólica del apego incondicional a la lengua propia, con la cuantificación absoluta "del mundo".

Aunque nuestro estudio se limita a los puristas castellanos de la época clásica, es impactante observar cómo los puristas de toda época y país comparten esta misma retórica, marcada por la hipérbole, los superlativos, el uso extraño del condicional, y la idea de la pérdida posible de la lengua. En el caso de la hipérbole, pensamos en la repetición del adverbio de eternidad "immer" por Hannah Arendt en su entrevista con Günter Gaus en 1964, para significar su apego visceral y paradójico a la lengua del Holocausto ${ }^{32}$. Ella evoca también el carácter irremplazable de la lengua materna ("rien ne remplace la langue maternelle"), como si pudiera ser abandonada por otra.

Encontramos el empleo del modo condicional asociado a la extraña hipótesis de la separación (o del reemplazo) de la lengua materna, que expresa la angustia de la pérdida, tanto en Villalón como en Arendt o Derrida. En El monolingüismo del otro, especie de autobiografía lingüística, en la que Derrida evoca su niñez en Argelia y su vínculo con la lengua francesa, marcado por el desgarro de una identidad judía perdida y por la imposición de una lengua colonial pero adorada, la lengua francesa, describe su apego, que califica de neurótico, a esta:

31. Viziana escribe "porque los no advertidos tornen sobre sí y vuelvan a su lengua natural, que con la teta mamaron, y no la dejen por otra del mundo, pues en su propiedad a muchas excede, según probaremos" (Viziana, 1951: 41).

32. "Hannah Arendt : L’Europe de la période pré-hitlérienne ? Je ne la regrette pas, soyez-en assuré. Que reste-t-il? Eh bien la langue reste.

Günter Gaus : Et cela a beaucoup d'importance pour vous?

Hannah Arendt: Oui, beaucoup. J'ai toujours consciemment refusé de perdre ma langue maternelle. [...] La langue allemande est toujours restée quelque chose d'essentiel que j'ai toujours conservé consciemment intact.

Günter Gaus : Même dans les temps les plus amers?

Hannah Arendt: Toujours. Je me disais : que peut-on y faire? Après tout, ce n'est pas la langue allemande qui est devenue folle. Et par ailleurs, rien ne remplace la langue maternelle." (Arendt, 2015: 34-35). 
Mon attachement au français a des formes que parfois je juge "névrotiques". Je me sens perdu hors du français. [...] Je ne suis pas seulement égaré, déchu, condamné, hors du français, j'ai le sentiment d'honorer ou de servir tous les idiomes, en un mot d'écrire le 'plus' et le 'mieux' quand j'aiguise la résistance de mon français, de la "pureté" secrète de mon français, celle dont je parlais plus haut, sa résistance donc, sa résistance acharnée à la traduction. [...] 'Intraduisible' demeure - doit rester, me dit ma loi - l'économie poétique de l'idiome, celui qui m'importe, car je mourrais encore plus vite sans lui [...]. (Derrida, 1996: 97-101)

El epíteto "acharné" y la repetición de "résistance" implican una defensa acérrima de la lengua propia, como si esta fuera amenazada. El epíteto "secreto" aplicado a "pureza" recuerda las líneas ya citadas de Milner sobre la lengua pura como tesoro que hay que guardar con esmero. La retórica hiperbólica, con la gradación "égaré, déchu, condamné” y la repetición de la palabra "français" asociada al posesivo en cursiva, expresan una identificación total del sujeto con su lengua. Sobre todo, en la oración "je mourrais encore plus vite sans lui" (yo moriría aún más rápido si no existiera la lengua francesa), la equivalencia de la muerte propia con la extinción imaginaria de la lengua delata una especie de neurosis psico-lingüística, en la que sujeto y lengua ya no constituyen sino una misma entidad. El individuo cristaliza su identidad en el idioma, que se vuelve parte o incluso encarnación de sí mismo.

\subsection{Adjetivos posesivos, identificación y comunidad lingüística}

George Thomas ya vinculaba la idea de amenaza exterior sobre la lengua con la de la aserción renovada de la pertenencia a un grupo ${ }^{33}$, y describía la lengua como encarnación de la identidad nacional:

According to the nationalist viewpoint, only the national language can adequately serve as symbol of self-identification with this national culture. Our native language is that form of speech which we recognize as "ours". That is why in some societies [...] it is not uncommon to use no more specific name for the language than "ours". (Thomas, 1991: 43)

Por supuesto no se trata de nacionalismo en el caso de Derrida, pero esta idea de identificación con la lengua y de demarcación entre lo "nuestro" y lo "suyo" ayuda a entender el apego purista a la lengua materna. Ello se expresa mediante el uso, recurrente entre los autores de nuestro corpus, del adjetivo posesivo de primera persona del plural: lo encontramos 127 veces asociado a la lengua

33. "The view that the language is exposed to a threat posed by some external source or from internal disintegration is based on the us/them, our/their dichotomies [...]" (Thomas, 1991: 47). 
(de las 150 ocurrencias en total) ${ }^{34}$, y la palabra aparece sobrerrepresentada entre los puristas (sobre todo en Morales -i33 veces!-).

Esta reiteración machacona del lema "nuestro" delata una posesividad celosa ${ }^{35}$, asociada con el miedo irracional a la pérdida de la lengua materna, a la par que la adhesión del locutor a una comunidad identitaria. El posesivo expresa entonces tanto la posesión (al considerar la lengua como bien propio del sujeto, pertenencia valiosa, tesoro personal) como la esencia (identificación total del sujeto con su lengua, auto definición en la que prevalece el idioma hablado).

En su libro The symbolic construction of community, el antropólogo Anthony Cohen describe así la comunidad como una entidad colectiva y simbólica que se define a sí misma mediante la diferenciación con el Otro, y su rechazo:

A reasonable interpretation of the word's ["community"] use would seem to imply two related suggestions: that the members of a group of people (a) have something in common with each other, which (b) distinguishes them in a significant way from the members of other putative groups. "Community" thus seems to imply simultaneously both similarity and difference. The word thus expresses a relational idea: the opposition of one community to other or to other social entities. (Cohen, 1995: 12)

\subsection{Erotización de la lengua mediante la personificación femenina}

Porque la lengua pura no tiene definición explícita entre los puristas, ellos van proyectando imágenes sobre esta. Una imagen recurrente es la de la mujer bella y casta: el imaginario purista se caracteriza por una erotización de la lengua y su personificación femenina.

Se encuentra esta erotización de manera implícita en la metáfora del afeite ${ }^{36}$ y del atuendo ${ }^{37}$ para designar el ornatus, y en las múltiples imágenes de la bella lengua poética como muchacha hermosa

34. Las fórmulas son muy variables: "nuestra lengua castellana" (11, o sea 8,7\% de los casos), "nuestra lengua" (72, o sea 57\% de los casos), "nuestra lengua vulgar" (1), "la nuestra española" (2), "nuestra habla" (2), "nuestra castellana lengua" (1), "la nuestra natural” (1), "nuestra lengua española" (1), "nuestra castellana española" (1), "nuestra lengua propia" (1), "nuestra habla natural" (1), "nuestra castellana" (1).

35. En otro pasaje, Derrida habla significativamente de "la garde jalouse qu'on monte auprès de sa langue" (Derrida, 1996: 105).

36. A propósito del "excesivo artificio de palabras": "la hermosura nativa suele engendrar sospecha de no muy natural, si la vemos adulterada con el exceso del afeite" (San José, 1951: 172); Medina habla de "la beldad de nuestra lengua (la cual, bien que desnuda y sin afeites, todavía se hallaban ojos a quien pareciese bien)" (Medina, 1951: 99); "Yo no digo que afeites nuestra lengua Castellana, sino que le laves la cara. No le pintes el rostro, mas quítale la suciedad; no la vistas de bordados ni reclamos, mas no le niegues un buen atavío de vestido que aderece con gravedad" (Morales, 1951: 53).

37. A propósito de la negligencia de sus contemporáneos: “[...] [dejan a la lengua] como si ella fuese tan fea que no mereciese más precioso ornamento, o nosotros tan bárbaros que no supiésemos vestirla del que merece" (Medina, 1951: 96); "Después [...] la compuso con ropas tan varias y tan lucidas, que ya la desconocen de vistosa y galana" (Medina, 1951: 100). 
(en Francisco Fernández de Córdoba, Cervantes), que no debe ser adornada de manera excesiva -aunque estas imágenes se apliquen más bien a la poesía que al idioma propiamente dicho-.

Sobre todo, se halla este imaginario erótico en metáforas de la lengua como esposa legítima, matrona honesta o virgen pura de toda mancha.

Así Lope de Vega Carpio, en las Epístolas de la Filomena, establece una analogía entre lengua propia-mujer legítima y lengua extranjera-prostituta, para desacreditar a los poetas que hacen préstamos léxicos: "no es enriquecer la lengua dejar lo que ella tiene propio por lo extranjero, sino despreciar la propia mujer por la ramera hermosa” (Lope de Vega Carpio, 2015: f. 198r). El vituperio de los poetas que utilizan palabras extranjeras se expresa mediante la doble antítesis "propio"/"extranjero", "propia mujer”/“ramera hermosa”. La fidelidad del poeta a su lengua materna se subraya por la imagen del vínculo sagrado y eterno del matrimonio.

En Francisco de Medina, tenemos una metáfora similar, pero más desarrollada. La lengua propia es mujer honesta, a la que cuesta mucho conquistar y que necesita ser larga y amorosamente cortejada:

se comenzará a descubrir más clara la gran belleza y esplendor de nuestra lengua; y todos encendidos en sus amores, la sacaremos, como hicieron los príncipes griegos a Elena, del poder de los bárbaros. Encogiérase ya de hoy más la arrogancia y presunción de los vulgares que, engañados con falsa persuasión de su aviso, osaran requestar atrevidamente esta matrona honestísima, esperando rendirla a los primeros encuentros, como si fuera una vil ramera y desvergonzada. (Medina, 1951: 101)

El pasaje es marcado por un soplo épico, con el uso del futuro profético ("se comenzará”, "sacaremos"), asociado a la comparativa mitológica en el pasado ("como hicieron los príncipes griegos a Elena”): la defensa heroica de la lengua vulnerable se asemeja a las batallas épicas de Troya ${ }^{38}$.

La tonalidad épica se subraya mediante una prosodia elaborada, con dos endecasílabos blancos: el primero, lírico ("gran bellez[a y e]splendor de nuestra lengua"39), recalca la hermosura de la lengua al colocar el énfasis en "esplendor", palabra oxítona ubicada en medio del verso, y después de una doble sinalefa que la pone de realce. El segundo, enfático ("todos encendidos en sus amores"), coloca el acento rítmico en el pronombre de totalidad "todos", expresando en forma hiperbólica un amor superlativo, mediante la elección del adjetivo "encendidos": se habla de la lengua como de la mujer por la que se siente una pasión erótica. Además de los dos endecasílabos blancos, la elaboración sintáctica es muy esmerada, con la puesta en aposición de la comparativa (“la sacaremos, como hicieron los príncipes griegos a Elena, del poder..."), que pone de realce la superposición imaginaria del tiempo del mito ("hicieron") y del futuro glorioso del salvador de la lengua ("la sacaremos”). El

38. No es un azar tampoco si la lengua se compara implícitamente con Elena, la más bella de todas las mujeres del mundo.

39. Marcamos aquí la doble sinalefa entre corchetes. 
pasaje se cierra con la metáfora de la lengua como matrona honesta ("esta matrona honestísima"), opuesta por antítesis al trato que recibe del pueblo ("requestar atrevidamente") expresada en la comparativa hipotética ("como si fuera una vil ramera y desvergonzada") que la opone a la lengua impura de los "bárbaros", mancillada, prostituida. Según Medina entonces, la propia lengua debe ser tratada con respeto; para hablarla y escribirla bien no basta con el trato cotidiano, sino que hace falta cuidado y miramiento.

Por fin, cuando Baltasar Echave de Orio, pintor y escritor vizcaíno instalado en Nueva España, publica allí sus Discursos de la antigüedad de la lengua cántabra vascongada $(1607)^{40}$, asimila la lengua vasca a una matrona abandonada. En este texto muy extraño, es la lengua vasca la que habla, reprochándoles a los suyos haberla dejado, al provecho de la lengua castellana. En esta bella y rara prosopopeya ("La lengua vascongada soy discreto lector, que con mi acostumbrada cortedad me pongo ante tus ojos"), se dirige a sus hijos, animándoles al amor a la lengua propia:

[...] [Mi discurso es] caseramente hecho a mis amados hijos: pues nunca el amor maternal mira tanto al modo con que les habla, cuanto a la sustancia de lo que les trata. Así te suplico, si alguna parte tienes de mi sangre, me recibas como propia [...]. (Echave Orio, 1607: f. 11).

Aquí la perspectiva es invertida y es la lengua la que siente "amor materno" a sus hijos. Si tenemos en cuenta la identificación psicológica de los puristas con su lengua, esta personificación impactante resulta no ser otra cosa sino el reflejo, proyectado e invertido, del amor del autor a su lengua ${ }^{41}$.

En estos pasajes asoma la idealización que los escritores hacen del idioma propio. Erotizada, asimilada a una matrona honesta, una virgen que corre peligro o una esposa leal, la lengua materna es siempre presentada como casta y frágil. Así, los puristas realizan una extraña sexuación de la lengua ${ }^{42}$, contradictoria con la afirmación reiterada (dos veces en nuestro corpus) de la masculinidad del idioma castellano ${ }^{43}$. Existe pues un imaginario heroico del locutor masculino que tiene que salvar a su lengua-mujer deseada, de los ataques tanto exteriores (préstamos y mezclas lingüísticas) como interiores (negligencia del vulgo y menosprecio de los sabios).

40. Le agradezco de todo corazón a la Profesora María Luisa Calero Vaquera la referencia.

41. Que menciona el mismo autor en el prólogo: "Esta consideración y el amor grande que a mi patria y lengua tengo, me han hecho fuerza a que tome la pluma en defensa de la antigua lengua española [el vasco]” (Echave Orio, 1607: f.7).

42. Helena Sanson estudió las representaciones de género que se asociaron con el estudio de la lengua desde 1500 hasta 1900. La gramática era muchas veces representada bajo rasgos femeninos, como en el pedestal del púlpito de la catedral de Pisa, esculpido por Giovanni Pisano entre 1302 y 1310, en el que aparece bajo los rasgos de una nodriza amamantando (Sanson, 2011: 5).

43. "[...] la serpiente en el Paraíso Terrenal habló en tudesco, cuando engañó a Eva, y Eva en italiano, y Adán en español, denotando la habla castellana por varonil, habla de hombre varón; la italiana, de mujer femenina; la tudesca, no humana, mal sonante y dura" (Correas, 1903: 165); "Si buscamos suavidad y dulzura, ella la tiene acompañada de gran ser y majestad, conveniente a pechos varoniles y nada afeminados" (Aldrete, 1606: 131). 
Esta temática de la castidad nos lleva hacia nuestro tercer núcleo temático, el de las representaciones que asemejan pureza lingüística, pureza corporal y pureza espiritual.

\section{Afinidad entre pureza lingüística, pureza corporal y pureza espiritual}

\subsection{Casticidad y castidad: afinidad léxica y peso de la religión en el uso lingüístico}

En esta tercera parte, se trata de reflexionar sobre una posible influencia del ámbito religioso en el ámbito lingüístico, a la hora de hablar de "pureza" de la lengua.

Un pasaje en nuestro corpus vincula de manera explícita pureza verbal y pureza moral:

Pero la nuestra lengua es grave, religiosa, honesta, [...] no sufre ni permite vocablos extraños y bajos, ni regalos lascivos; es más recatada y observante, que ninguno tiene autoridad para osar innovar alguna cosa con libertad. (Herrera, 1580: 89)

La lengua propia es honesta por esencia, se distingue de lo "lascivo", alejado del recato asociado con la lengua materna, o sea de lo sucio e impuro por excelencia en la mentalidad cristiana: la sensualidad carnal.

Los autores del corpus emplean de manera significativa las mismas palabras para hablar de la pureza moral y la pureza lingüística: "limpieza y honestidad" y "casto, limpio" aparecen en Malón de Chaide, aplicados al contenido de los libros de caballería (pureza moral)"44 y Herrera menciona la "castidad" de la lengua ${ }^{45}$. Esto se debe a la polisemia de la palabra "castidad", que significa tanto "casto, castizo, puro, para hablar de la lengua", como "cualidad del que se abstiene de gozo carnal". La reversibilidad de la palabra, desde lo moral hacia lo lingüístico, puede sugerir un vínculo entre ambos significados: en la palabra "castidad" se reúnen estos dos polos simbólicos de lo castizo, lo auténtico, lo idiomático, lo realmente castellano, lo acendrado, y lo decente, lo puro, lo recatado.

Esta afinidad entre pureza moral y pureza lingüística se encuentra en la corriente de eufemización que ocurrió en los siglos XVI y XVII: se purgó paulatinamente la lengua del léxico del cuerpo, y, aunque ello no fue actividad consciente de individuos puristas, es síntoma de una tendencia a la censura lingüística ${ }^{46}$ en la época moderna. El vínculo entre eufemismos y purismo lingüístico ya fue notado

44. "[...] son amores tratados con limpieza y mucha honestidad" (Malón de Chaide, 1603: 78). "[...] todo lo que hay allí es casto, limpio, santo, divino y celestial, y lleno de misterios" (Malón de Chaide, 1951: 79).

45. Hablando de la lengua castellana: "toda entera y perpetua, muestra su castidad y cultura, admirable grandeza y espíritu, con que accede sin proporción a todas las vulgares" (Herrera, 1951: 89).

46. Keith Allan y Kate Burridge hablan de "language censoring" y de "verbal hygiene" (Allan y Burridge, 2006: 112). 
por Keith Allan y Kate Burridge en su monografía sobre los tabúes verbales (Allan y Burridge, 2006: 112).

Este fenómeno se puede relacionar con la mentalidad cristiana de rechazo al cuerpo. Juan Goytisolo, en su interesantísimo artículo sobre la "coprofilia" quevediana, analiza los procesos culturales de "sublimación" del cuerpo, que equivalen a su represión y aniquilación (Goytisolo, 1976). Describe la "humillación paulatina del valor del cuerpo" (Goytisolo, 1976: 38-39) y lo vincula al cristianismo47 (Goytisolo, 1976: 39), que opone a la sensualidad gozosa de la sociedad musulmana de la España medieval. Habla del paradójico vínculo que hacían los cristianos entre suciedad corporal (los cristianos tenían que distinguirse de los musulmanes, y en ese sentido la de los baños era una actividad culturalmente connotada) y pureza espiritual (la atención al cuerpo inducía al pecado, por lo que aquel debía ser sofocado), por lo que el cuerpo debía permanecer sucio; fue así como se suprimieron los termas y baños públicos en 1526 y 1576.

\subsection{Sacralización y transgresión del tabú lingüístico: vistazo al caso singular de Francisco de Quevedo}

Frente a esta obliteración del cuerpo, algunos autores, paradójicamente puristas (o parcialmente puristas) ${ }^{48}$, intentaron liberar el habla de las trabas cristianas para "devolver la voz al cuerpo" (Goytisolo, 1976: 40).

47. "religión que rehúsa el cuerpo y la felicidad de los sentidos" (Goytisolo, 1976: 39).

48. Así se puede calificar a Quevedo por su rechazo de las expresiones vulgares y por los pasajes sobre la impureza constitutiva de los orígenes, mezclados, de su lengua, en la España defendida. Vamos a ver a continuación que su caso es más complejo de lo que parece. 
Tomamos por ejemplo el soneto 535 de Francisco de Quevedo, en la edición de Blecua:

La vida empieza en lágrimas y caca, luego viene la mu, con mama y coco, síguense las viruelas, baba y moco, y luego llega el trompo y la matraca. En creciendo, la amiga y la sonsaca: con ella embiste el apetito loco; en subiendo a mancebo, todo es poco, y después la intención peca en bellaca. Llega a ser hombre, y todo lo trabuca; soltero sigue toda perendeca; casado se convierte en mala cuca. Viejo encanece, arrúgase y se seca; llega la muerte, y todo lo bazuca, y lo que deja paga, y lo que peca. ${ }^{49}$

En este poema disfemístico ${ }^{50}$, el autor se complace en violar todos los posibles tabúes lingüísticos que impedían nombrar actividades corporales como la defección. Nombra de manera cruda, sin desvíos eufemísticos algunos, los líquidos y excreciones corporales (lágrimas, caca, baba, moco), aquellos que según los antropólogos constituyen la encarnación antonomástica de lo impuro ${ }^{51}$.

Desde el punto de vista prosódico, estas palabras disonantes son puestas de realce en finales de versos, lo que da un efecto de caída grosera e inesperada. El recurso a palabras de carácter onomatopéyico, infantil y familiar (caca, mama, coco, baba, moco), dan la impresión de un discurso regresivo $0^{52}$.

Aquí las distinciones de Keith Allan y Kate Burridge nos pueden resultar útiles para entender el grado de obscenidad del soneto quevediano. Ellos distinguen entre ortofemismo ("straight talking"), eufemismo ("sweet talking") y disfemismo ("speaking offensively") (Allan y Burridge, 2006: 29). Dan como ejemplo "faeces", ortofemismo de "poo" (eufemismo) y "shit" (disfemismo); el disfemismo, categoría que nos interesa aquí, designa entonces "a word or phrase with connotations that are offensive either

49. Quevedo, 1995: 18.

50. Ver la definición del "disfemismo" más abajo.

51. Por híbridos, por colocarse en el margen del cuerpo, perteneciendo a la vez a lo interior y lo exterior. Lo apuntan tanto Edmund Leach, como Larry Grimes, citado por Juan Goytisolo (Goytisolo, 1976: 38), y Mary Douglas (Douglas, 1966: 42). He aquí lo que escribe Edmund Leach al respecto: "[...] the exudations of human body are universally the objects of intense taboo - in particular feces, urine, semen, menstrual blood, hair clippings, nail parings, body dirt, spittle, mother's milk. This fits the theory. Such substances are ambiguous in the most fundamental way. The child's first and continuing problem is to determine the initial boundary. 'What am I, as against the world?' 'Where is the edge of me?'. In this fundamental sense, feces, urine, semen, and so forth, are both me and not me" (Leach, 1989: 38).

52. La obscenidad verbal puede interpretarse tanto como tendencia regresiva, como como pura expresión poética. Así, Milner, en L'amour de la langue, llamaba estos momentos de "verdad" poética "puntos de poesía": "[...] l'acte de poésie consiste à transcrire dans la langue même et par ses voies propres un point de cessation du manque à s'écrire. C'est en quoi la poésie a affaire à la vérité, puisque la vérité est, de structure, ce à quoi la langue manque [...]. [...] Il est facile de reconnaître, dans la tradition critique, divers noms du point de cessation, qu'on pourrait aussi dire point de poésie : pour tel, c'est la mort, pour tel l'obscène, pour tel le sens plus pur, que l'on atteint en arrachant les mots au cercle de la référence ordinaire - ce qu’on désigne comme hermétisme." (Milner, 1978: 38-39). 
about the denotatum and/or the people addressed or overhearing the utterance" (Allan y Burridge, 2006: 31). Desgraciadamente, resulta bastante difícil aplicar esta distinción a textos españoles de los siglos XVI y XVII, porque no se sabe exactamente cuál fue la variante ortofemística. Desde el punto de vista lingüístico, sólo "caca” aparece abiertamente disfemístico aquí, y vamos a ver por qué.

Una búsqueda de la palabra "caca" en el CORDE resulta interesante para entender el uso quevediano de la palabra. Esta aparece 56 veces entre 1500 y 1660.

Las instancias se pueden clasificar en tres grupos mayores. Primero, el vocablo "caca" se ve claramente asociado con los primeros chapurreos de los niños: es el caso en unas comedias, en las que la expresión onomatopéyica está utilizada para dirigirse a un niño $0^{53}$, o por el niño mismo ${ }^{54}$, asociado con otras palabras infantiles ("Papa", "coco", "mama”, "moco"). Dos veces aparece en la expresión estereotipada "no saber decir la caca", que designa a un niño que todavía no sabe hablar ${ }^{55}$, o un perro, que no puede pronunciar sonidos humanos ${ }^{56}$. En el último caso de este primer grupo, se asocian las

53. Hablando de un niño: “Qué dijo? ¿Papa, caca?” (Lope de Vega, El rey Bamba, entre 1590 y 1598). En un pasaje de Don Pegote (1643) de Calderón de la Barca, tenemos apóstrofes a un niño, asociados con el imperativo hipocorístico "daca", y el "desliz" de don Pegote, que hace eco al "daca" de doña Quínola con un "caca" mucho más ofensivo, lo que lo lleva a comentar "lo dicho dicho" para justificar esta licencia, como si le escapara la palabra:

"DOÑA QUÍNOLA Bueno está. Daca, niño, daca, daca.

DON PEGOTE Daca tras, niño, caca, caca.

Lo dicho dicho; y basta, mis harpías,

madres en el tomar, en pedir, tías."

54. En el Entremés del Niño y Peralvillo de Madrid (1622), de Quevedo:

"Manuela: ¡Ay, qué linda criatura!

María: ¡Ay, cómo llora!

Los dientes deben de salirle agora.

Dame la bolsa, y quitaréte el moco.

Niño: ¿Dame la bolsa? Coco, coco, coco.

Manuela: Mil sales tienes; eres lindo: daca.

Niño: ¿Daca tras lindo? Caca, caca, caca.

Manuela: ¡Oh, qué mal niño eres!

No veo que a darme nada te acomodes.

Lástima fue no dar contigo Herodes"

En este ejemplo, la única pronunciación de la palabra "caca" provoca el vituperio inmediato (“iOh, qué mal niño eres!"), como reacción a lo indecible, lo vedado. Aun en boca de niños, el vocablo resulta chocante. También en la comedia anónima La ventura sin buscarla (1650), en la que otra vez aparecen onomatopeyas de infans:

"INFANTA Andad, volvedle a su ama.

NIÑO Coco, taita; caca, mama.

CONDE ¡Los diablos Ileven tu alma!

¡Bendígate Barrabás!”

55. “Vuélvese a niño, que no sabe decir la caca?” en La Pícara Justina (1605).

56. En una anécdota incluida en la Filosofía antigua poética (1596) de López Pinciano, en la que un filósofo tiene que cuidar a una perrilla: "icuál sería bien que la criatura ahíta y que no sabía decir la caca, dejase a la lana del pobre filósofo!". 
heces a la suciedad infantil ("nalgas de niño llenas de caca") 57 . En el segundo grupo, la palabra es muy significativamente tematizada como algo indecible, como tabú: "que mujeres no saben callar cosa, aunque sea la caca y el coco y el cuco" (La Pícara Justina), y, en un romance burlesco, "Mirad que digáis la caca" 58 , al dirigirse a una mujer. Por fin, aparece en la picaresca como recurso burlesco ${ }^{59}$.

A la vista de estos empleos, creo que "caca" resulta bastante inesperado (recordemos el "Mirad que digáis la caca") y ofensivo en boca de un adulto, por lo que podríamos hablar de variante disfemística de las designaciones ortofemísticas "andar del cuerpo", "hacer uno de su persona", "hacer del cuerpo" "obrar"60. De manera interesante, en el Siglo de Oro, el eufemismo ("andar del cuerpo", etc.) se tornó ortofemismo.

En Quevedo, estos disfemismos suenan como una voluntad de profanación del habla pura. Sus poemas escatológicos dan la impresión de una liberación alegre de las trabas cristianas ${ }^{61}$, pero quizás también se pudieran interpretar como deseo de transgredir su propia concepción de la lengua perfecta. Freud no definía de otra manera el tabú en su clásico Totem y Tabú (1912): una prohibición que conlleva el deseo irreprensible de transgredirla y unos sentimientos ambivalentes ante una cosa deseada a la par que aborrecida. He aquí la definición de Freud:

Le tabou est une prohibition très ancienne, imposée du dehors (par une autorité) et dirigée contre les désirs les plus intenses de l'homme. La tendance à la transgresser persiste dans son inconscient; les hommes qui obéissent au tabou ont une ambivalence à l'égard de ce qui est tabou. (Freud, 2002: 46) ${ }^{62}$

En este sentido, el soneto citado es elocuente con respecto a las contradicciones y complejidades de la mentalidad purista, hecha de un amor tan fuerte que se puede tornar patológico y desembocar en profanación de la pureza lingüística anhelada. Quevedo se caracteriza en sus obras por esta rela-

57. Sólo doy aquí el final: "¿Quién ve las narices sucias con la basura, que no imagine son nalgas de niño llenas de caca? ¡hombre, si quieres conservar tu juicio arroja el tabaco, porque sino perderás el seso y quedará tu cabeza vana.” (Bartolomé Jiménez Patón, Reforma de trajes, 1635-1638).

58. "Mirad que digáis la caca, porque no se alabe Esgueva, de que vio vuestros pañales tendidos en su ribera", en una Relación de fiestas de 1605.

59. En el Guzmán de Alfarache, en el que el protagonista intenta esconder que hizo del cuerpo en la cama, y en el Buscón, muy inspirado en el pasaje de Mateo Alemán.

60. Tenemos sin embargo que precisar que, de manera extraña, no hemos encontrado huellas de estas expresiones en el CORDE.

61. Juan Goytisolo entendió este afán transgresivo del autor como una manera de exorcizar el tabú lingüístico impuesto por las normas puristas.

62. Escribe también : "le maintien du tabou a eu pour effet que le désir primitif de faire ce qui est tabou a persisté chez ces peuples. Ceux-ci ont donc adopté à l'égard de leurs prohibitions tabou une attitude ambivalente; leur inconscient serait heureux d'enfreindre ces prohibitions, mais ils craignent de le faire; et ils le craignent parce qu'ils voudraient le faire, et la crainte est plus forte que le désir." (Freud, 2002: 43). 
ción ambivalente, de amory odio simultáneos, por la lengua materna: sus afanes por limpiarla de las escorias populares chocan con sus escritos groseros, en los que parece complacerse en "ensuciar" la lengua adorada. Se trata aquí de un caso sin duda singular, pero nos interesa porque confirma nuestra hipótesis de sacralización purista de la lengua: lo conservamos como ejemplo de una actitud purista extrema.

\section{Conclusión}

El purismo sería pues menos un conjunto de doctrinas explícitas y coherentes, que una actitud frente a la lengua propia, hecha de atracción y fascinación, una relación particular con esta que se expresa mediante metáforas e imágenes. Siendo una actitud irracional de valorización de la lengua materna, resulta normal que se proyecte bajo formas imaginadas, y que no fuera objeto de un discurso científico ${ }^{63}$. Hemos echado luz a este peculiar "imaginaire" purista, a través de un examen de las metáforas de la frontera y de la suciedad. Esta relación particular de los puristas con su idioma se corresponde con un "amor a la lengua", expresado por el léxico de la adoración y del tesoro, una retórica hiperbólica, con el uso de estructuras superlativas, y la omnipresencia del posesivo "nuestro", que delata un apego obsesivo y casi neurótico a la lengua materna. Erotizada, esta se vuelve objeto del deseo purista a través de personificaciones femeninas, siempre expresivas de su fragilidad, sintomáticas de un miedo irracional a la pérdida. Por fin, la afinidad léxica entre castidad y casticidad, así como la omnipresencia del ideal de pureza en los siglos XVI y XVII, pudo empujar a los puristas a proyectar valores morales sobre el habla, ahora sometida a numerosas prohibiciones. Estas se dan a luz en los numerosos eufemismos que caracterizan la lengua de la época, que tiene que ser tanto castiza como casta. La liberación verbal de algunos individuos excepcionales por sus juegos lingüísticos transgresivos puede funcionar como otra prueba más de este peso posible de la religión cristiana en la lengua, así como de la sacralización purista de la lengua: lo puro se vuelve tabú y apela su transgresión.

63. Es precisamente lo que distingue lo "metalingüístico" de lo "epilingüístico" (Langer y Davies, 2005: 11), manifestación dentro del discurso de evaluaciones subjetivas sobre el idioma. 


\section{Bibliografía}

\section{Fuentes primarias}

Aldrete, Bernardo de (1606), Del origen y principio de la lengua castellana, o romance que hoy se usa en España, Roma, Impreso por Carlo Vulietto.

Anónimo (fecha desconocida), Equívocos morales del doctor Viana, en Germán Bleiberg (1951), Antología de elogios de la lengua española, Madrid, Ediciones Cultura Hispánica, p. 103-108.

Arias Montano, Benito (1570), Carta del doctor Montano al duque de Alba, hecha en Amberes a 18 de mayo de 1570, en Germán Bleiberg (1951), Antología de elogios de la lengua española, Ediciones cultura hispánica, p. 71-74.

Bleiberg, Germán (1951), Antología de elogios de la lengua española, Madrid, Ediciones Cultura Hispánica ${ }^{64}$.

Cabrera de Córdoba, Luis (1877), Felipe Segundo rey de España, Madrid, Impreso por Aribau y Compañía [Escrito en 1619].

Cervantes de, Miguel (2011), La Galatea, en Francisco López Estrada y María Teresa López García-Berdoy (eds.), Madrid, Cátedra [Edición de Francisco López Estrada y María Teresa López García-Berdoy, $1^{\text {ra }}$ edición, 1585].

Correas, Gonzalo (1903), Arte grande de la lengua castellana, Madrid, Impreso por Ricardo Fé. [Escrito en 1626]

Fonseca, fray Cristóbal de (1596), Primera parte de la Vida de Cristo Nuestro Señor en Germán Bleiberg (1951), Antología de elogios de la lengua española, Madrid, Ediciones Cultura Hispánica, p. 113119.

Herrera de, Fernando (1580), Anotaciones a las obras de Garcilaso de la Vega, Sevilla, Impreso por Alonso de la Barrera.

León de, fray Luis (1907), De los nombres de Cristo, Madrid, Biblioteca del Apostolado de la Prensa. [Escrito en 1583].

Malón de Chaide, Pedro (1603), Libro de la conversión de la Magdalena, Alcalá, Impreso por la viuda de Juan Gracián.

Medina de, Francisco (1580), Prólogo a las Anotaciones de Herrera a Garcilaso de la Vega, en Fernando de Herrera (1580), Anotaciones a las obras de Garcilaso de la Vega, Sevilla, Impreso por Alonso de la Barrera.

Mejía, Pedro (1570), Silva de varia lección, Sevilla, Impreso por Hernando Díaz. [Escrito en 1540]

64. Indicamos, cuando existen, ediciones consultables en la Biblioteca Digital Hispánica (todas las que no comporten la mención "en Germán Bleiberg...”). 
Morales de, Ambrosio (1550), Discurso sobre la lengua castellana en Germán Bleiberg (1951), Antología de elogios de la lengua española, Madrid, Ediciones Cultura Hispánica, p. 43-65.

Nebrija de, Antonio (1492), Gramática castellana, Salamanca, Impreso por Juan de Porras.

Pellicer de Ossau y José Tovar (1672), Población y lengua primitiva de España, recopilada del aparato a su monarquía antigua en los tres tiempos, el adelón, el mítico y el histórico, en Germán Bleiberg, Antología de elogios de la lengua española, Madrid, Ediciones Cultura Hispánica, p. 179-202.

Robles, Juan de (1992), El culto sevillano, Sevilla, Secretariado de publicaciones de la Universidad de Sevilla, Alejandro Gómez Camacho (ed.) [Escrito en 1631].

San José, Jerónimo de (1651), Genio de la Historia, en Germán Bleiberg (1951), Antología de elogios de la lengua española, Madrid, Ediciones Cultura Hispánica.

Valdés de, Juan (1957), Diálogo de la lengua, Modena, Società Tipografica Modenese, Edición de Lore Terracini. [Escrito en 1535]

Vega, Pedro de (1606), Declaración de los siete psalmos penitenciales, en Germán Bleiberg (1951), Antología de elogios de la lengua española, Madrid, Ediciones Cultura Hispánica, p. 135-143.

Venegas del Busto, Alejo (1553), Breve declaración de las sentencias y vocablos oscuros que en el libro del Tránsito de la Muerte se hallan in Agonía del Tránsito de la Muerte, Toledo, Impreso por Juan de Ayala.

Villalón de, Cristóbal (1558), El Escolástico, en Germán Bleiberg (1951), Antología de elogios de la lengua española, Madrid, Ediciones Cultura Hispánica, p. 33-37.

Viziana de, Rafael Martín (1574), Libro de alabanzas de las lenguas hebrea, griega, latina, castellanay valenciana, Valencia, Impreso por Juan Navarro.

\section{Textos añadidos}

Echave de Orio, Baltasar (1607), Discursos de la antigüedad de la lengua cántabra vascongada, México, Henrico Martínez.

Jáuregui, Juan de (2016), Discurso poético, Paris, Labex OBVIL, disponible en http://obvil.sorbonne-universite.site/corpus/gongora/1624_discurso-poetico\#body-1. [Sitio consultado el 8 de abril de 2018.]

Jiménez Patón, Bartolomé (1993), Elocuencia española en arte, Barcelone, Puvill libros.

Lope de Vega Carpio, Félix (2015), Epístolas de la Filomena, Paris, Labex OBVIL, disponible en http:// obvil.sorbonne-universite.site/corpus/gongora/1621_censura-lope\#body-1. [Sitio consultado el 8 de abril de 2018.]

Quevedo, Francisco de (1987), "Cuento de cuentos", en Pablo Jauralde Pou (ed.), Obras festivas, Madrid, Castalia, p. 149-169. 
Quevedo, Francisco de (1995), Poesía completa, tome II, José Manuel Blecua (ed.), Madrid, Turner.

\section{Textos tomados del CORDE}

Anónimo (2003), La ventura sin buscarla, Pamplona, Universidad de Pamplona, Ed. de Ignacio Arellano [Escrito c. 1650].

Anónimo (2000), Relación de las fiestas que la imperial ciudad de Toledo hizo al nacimiento del príncipe nuestro señor, Madrid, CORDE, Ed. de Abraham Madroñal Durán [Escrito en 1605].

Calderón de la Barca, Pedro (1982), Don Pegote, Madrid, Castalia, Ed. de Evangelina Rodríguez y Antonio Tordera [Escrito en 1643].

Jiménez Patón, Bartolomé (2004), Reforma de trajes, Madrid, Real Academia Española, Ed. de Abraham Madroñal Durán [Escrito en 1635-38].

López de Úbeda, Francisco de (1977), La pícara Justina, Madrid, Editorial Nacional, Ed. de Antonio Rey Hazas [Escrito en 1605].

López Pinciano, Alonso (1953), Filosofía antigua poética, Madrid, CSIC, Ed. de Alfredo Carballo Picazo [Escrito en 1596].

Quevedo y Villegas, Francisco de (1981), Entremés del niño y Peralvillo de Madrid, Madrid, Castalia, Ed. de José Manuel Blecua [Escrito en 1622].

Vega Carpio, Lope de (1996), El rey Bamba, Edición electrónica (S.L.), [Escrito en 1590-98].

\section{Fuentes secundarias}

Allan, Keith et Burridge, Kate (2006), Forbidden words: taboo and the censoring of language, Cambridge, Cambridge University Press.

Arendt, Hannah (2015), La langue maternelle, Paris, Eterotopia France.

Binotti, Lucia (1995), La teoría del "castellano primitivo": nacionalismo y reflexión lingüística en el Renacimiento español, Münster, Nodus Publkationen.

Bourdieu, Pierre et Luc Boltanski (1975), "Le fétichisme de la langue”, Actes de la recherche en sciences sociales, vol. 1, n4, p. 2-32.

Caillois, Roger (1950), L'homme et le sacré, Paris, Gallimard.

Canut, Cécile (1998), "Pour une analyse des productions épilinguistiques", Cahiers de praxématique, n³1, p. 69-90.

Cohen, Anthony Paul (1995), The symbolic construction of community, Londres/New York, Routledge.

Derrida, Jacques (1996), Le monolinguisme de l'autre, Paris, Galilée. 
Douglas, Mary (1998), "La pureté du corps", Terrain : anthropologie et sciences humaines, n³1, p. 5-12.

Douglas, Mary (1966), Purity and danger, Londres, Routledge \& Kegan Paul.

Durkheim, Émile (2015), Les formes élémentaires de la vie religieuse, Paris, Classiques Garnier.

Freud, Sigmund (2002), Totem et Tabou: interprétation par la psychanalyse de la vie sociale des peuples primitifs, Jean-Marie Tremblay (ed.), disponible en http://classiques.uqac.ca/classiques/freud_ sigmund/totem_tabou/totem_et_tabou_SV.pdf. [Sitio consultado el 12 de abril de 2018.]

Frevel, Christian y Nihan, Christophe (ed.) (2013), Purity and the forming of religious traditions in the ancient Mediterranean world and ancient Judaism, Leiden/Boston, Brill.

Goytisolo, Juan (1976), "Quevedo: la obsesión excremental”, Triunfo, n710, p. 38-42.

Houdebine, Anne-Marie (ed.) (2002), L'imaginaire linguistique, Paris, L'Harmattan.

Jankélévitch, Vladimir (1960), Le pur et l'impur, Paris, Flammarion.

Jenny, Laurent (2005), "La langue, le même et l'autre", Fabula-LhT, disponible en http://www.fabula. org/ht/0/jenny.html. [Sitio consultado el 8 de abril de 2018.]

Jervis Jones, William (1995), Sprachhelden und Sprachverderber. Dokumente zur Erforschung des Fremdwortpurismus im Deutschen (1478-1750), Berlin/New York, Walter de Gruyter.

Langer, Nils, et Davies, Winifred (2005), Linguistic purism in the Germanic languages, Berlin/New York, Walter de Gruyter.

Leach, Edmund (1989), "Anthropological aspects of language: animal categories and verbal abuse", in Eric Lenneberg (ed.), New directions in the study of language, Cambridge, The M.I.T. Press.

Milner, Jean-Claude (1978), L'amour de la langue, Paris, Seuil.

Mirambel, André (1958), "Essai sur la notion de conscience linguistique", Journal de psychologie normale et pathologique, n 55, p. 266-301.

Paveau, Marie-Anne y Laurence Rosier (2008), La langue française: passions et polémiques, Paris, Vuibert.

Sanson, Helena (2011), Women, language and grammar in Italy: 1500-1900, Oxford/New York/Auckland, Oxford University Press.

Siouffi, Gilles y Steuckardt, Agnès (ed.) (2007), Les linguistes et la norme: aspects normatifs du discours linguistique, Bern/Berlin/Bruxelles, Peter Lang.

Thomas, George (1991), Linguistic purism, Londres/New York, Longman.

Vitale, Maurizio (1986), L'oro nella lingua: contributi per una storia del tradicionalismo e del purismo italiano, Milan, R. Ricciardi ed. 
Woolard, Kathryn (2002), "Bernardo de Aldrete and the Morisco problem: a study in early modern Spanish language ideology", Comparative studies in society and history, vol. 44, n³, p. 446-480. 